\title{
Dancing on the volcano: social exploration in times of discontent
}

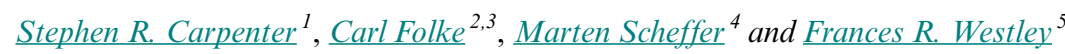

\begin{abstract}
Radical recent developments such as Brexit, the rise of extreme nationalism, the gilets jaunes, polarizing leaders, the Arab Spring, and fundamentalist movements are indications of societal discontent with the status quo. Other societal phenomena such as gender fluidity, veganism, and bartering are also associated with a perceived need to change. The context is the Anthropocene, a humandominated biosphere challenging the resilience of a livable planet. Such a broad set of developments may be interpreted in the light of new insights from theory of complex systems about what happens as resilience of the current pathway (societal organization as we know it) decreases. Rising fluctuations characterize a phase of uncertainty and exploration, potentially leading into a transition of the system toward a new pathway. We reflect on global changes that may contribute to social destabilization such as rising wealth concentration and environmental degradation and ask how responses may be understood from social-psychological forces such as the need for group identity and managing the terror of mortality. The emerging image is that of a society engaged in multifaceted experimentation. Maintaining such experimentation may help inspire novel pathways to desirable futures, but there is a risk of societies becoming trapped in backward-looking narratives that threaten long-term sustainable outcomes.
\end{abstract}

Key Words: Anthropocene; complex systems; pathways; resilience; terror management theory, transformation

\section{INTRODUCTION}

The music's playing, the notes are right

Put your left foot first and move into the light

The edge of this hill is the edge of the world

And if you're going to cross you better start doing it right

Better start doing it right

You better start doing it right

Let the dance begin

Dance on a Volcano

Genesis - A Trick of the Tail 1976

The human dimension has accelerated in scale, connectivity, and speed to the extent that humans now shape the dynamics of the Earth system and its biosphere (Steffen et al. 2018). There is pervasive human-driven change in ecosystem structure across the planet and in the cycles of essential nutrients that all species rely on (Schlesinger and Bernhardt 2013). Humans constrain the evolution of plants and animals (Hendry et al. 2017), and an ever more rapidly developing technological capacity interacts with the biosphere. The Anthropocene biosphere is developing into something fundamentally different (Ellis 2015, Williams et al. 2015). There is something new under the sun.

In the Anthropocene biosphere, humans and nature have evolved into a truly intertwined complex system operating in new, and in some respects unknown, terrain. There are challenging and uncertain futures for a globally connected human population growing past 8 billion. Projections of global warming push the possibility of widespread famine and cascading environmental crises even closer (Wheeler and von Braun 2013, Biggs et al. 2018). Divergence or variability in many dimensions of human activity, like the political, cultural, and economic spheres seems to have increased. As fluctuations grow and instabilities appear there are increasing possibilities for major systemic transformations, not all of which are desirable.

In the language of complex dynamical systems, transformations are major shifts in pathways of development, as old paths fall out of favor and new ones are adopted. Transformation is seen by some scholars as the consequence of societal collapse and others see the capacity to transform as an essential property of longlasting social-ecological systems (Feola 2015). The latter form of transformation draws on resilience from multiple scales and diverse actors and organizations. It requires the capacity to learn with change, allow space for experimentation, deepen and scale up successful experiments, and navigate transitions across thresholds (Folke et al. 2010, Westley et al. 2011).

One of the signs of a complex system in transition, discussed in greater depth in the next section, is a pattern of flickering: shortduration shifts into new attractors (Scheffer et al. 2012). Flickering occurs when the envelope of variability around the system pathway is bigger than the difference between alternative pathways (Brock and Carpenter 2010). In ecosystems, an example is the highly variable path of change in fish and plankton of lakes during a trophic cascade between alternate states (Carpenter et al. 2011). In social systems, the equivalent may be rapid but shallow enthusiasm referred to as fads or crazes (Smelser 1963). This behavior is a sign of the current system becoming more fragile. The question remains whether such experimentation can result in real innovation and sustainable transformation.

The hope for the future, of course, is that new alternative pathways for development in the Anthropocene will be created. Much interest in social experimentation and innovation in the last decade has identified possibilities for a "good Anthropocene" (Westley et al. 2011, Bennett et al. 2016). However the question

\footnotetext{
${ }^{1}$ Center for Limnology, University of Wisconsin-Madison, Madison, WI, USA, ${ }^{2}$ Stockholm Resilience Centre, Stockholm University, Sweden, ${ }^{3}$ Beijer Institute, Royal Swedish Academy of Sciences, Sweden, ${ }^{4}$ Department of Environmental Sciences, Wageningen University \& Research, Wageningen, The Netherlands, ${ }^{5}$ Waterloo Institute for Social Innovation and Resilience and School for Environment, Enterprise and Development, University of Waterloo, Kitchener, ON, Canada
} 
remains whether these alternatives can mature quickly enough to offer real pathways for transformation or viable alternatives to the unstable status quo (Westley et al. 2017).

There are many indications that the industrial era is losing resilience and approaching its end. For example, energy futures are hotly debated between advocates of continued subsidies to the fossil fuel industry and those favoring development of renewable options. Organizations at many scales, from individual businesses to cities to nations, are declaring goals of "carbon neutrality."

Another sign of instability and searching is the great deal of social experimentation that is underway. On the surface this would seem to challenge the current economic, political, and social order. Some movements that have received considerable media and social media attention include gender ambiguity and hypersensitivity, veganism and other lifestyle diets, minimalism, and bartering. It has been argued that these movements are motivated by intense anxiety and identity ambiguity, which links them, potentially, to existential anxiety about the status quo (Lukianoff and Haidt 2018). But do these really challenge the status quo or will they remain at a small group level? Might some experimentation potentially contribute to the growing crisis? In the economic world the introduction of bitcoin currencies and the sharing economy would seem on the surface to offer challenges to the old way of doing things, but may create surprises such as accelerated warming (Mora et al. 2018). At the same time others are abandoning all hope of changing and seem to be seeking an escape from the mounting complexity of our time into the felt certainty of the past. Examples of attraction to memories of the past are Brexit, Trump, the rise of nationalist parties in developed nations, and fundamentalist movements like the Islamic State. As these social experiments are ongoing, the biophysical systems that support life on earth are changing in unprecedented ways and some seem to be losing resilience as they approach tipping points. The turbulent dynamics of approaching an interconnected socialecological threshold (a changing society while our life-support system is increasingly fragile) is fraught with both peril and possibility. We equate it with "dancing on the volcano." Here, through the lens of complex dynamical systems, we discuss the declining resilience of the current pathway of societal development and the prospect for emergence of new pathways.

\section{A DYNAMICAL SYSTEMS VIEW}

One way to make sense of the global emergence of exploration is to view it as the symptoms of a complex system that is losing stability. Specifically, as dynamical systems approach a tipping point they tend to start fluctuating more wildly. This happens because the status quo loses resilience. As a result, return to that state upon perturbations becomes slower (a phenomenon known as "critical slowing down"), and transient shifts to alternative configurations become more frequent (so-called "flickering"; Scheffer et al. 2012). The mathematical theory behind such dynamical indicators of resilience (DIORs) has been developed largely on the basis of simple models with only one or two variables. However, the theory is generic, and those indicators have indeed been observed across a wide range of complex systems including ecosystems, the human mood system, and the climate (Scheffer et al. 2012).
Clearly, societies are very complex and social dynamics have numerous relevant dimensions, such as religion, consumer behavior, political choices. Moreover, humanity is organized in a complex web of subgroups, both geographically, e.g., countries, and socially, through multiple group memberships, e.g., class, gender, kinship, politics, and lifestyles. Despite this complexity we may get an intuitive feel for the dynamical effects of increasing instability from a "volcano model" (Fig. 1). The complex state of society is represented in an intuitive, if overly simple, way as the position of a ball in a "stability landscape" where the valleys are attractors. The slopes represent the speed at which the system tends toward the valley. The state of a society where the vast majority is content with the status quo may be depicted as a deep valley with steep slopes represents a very resilient attractor (the stability landscape up-front in the figure). Upon perturbations the system will move back to the attractor, and it would take a lot of energy to push the system out of the basin of attraction. Mechanisms for stabilizing such a resilient societal status quo are obviously complex, encompassing among other things the institutional settings, cultural dimensions, and power structures. These complexities can be built into the model but the generic behavior will remain.

Fig. 1. Schematic representation of the hypothesized change over the past half century from a dominant social attractor to a situation where the attractiveness of this status quo has declined and social exploration of alternative options becomes more common. The horizontal axis represents a onedimensional projection of the way society is organized. Slopes in these stability landscapes correspond to rates of change (Scheffer et al. 2012). The deeper the valley, the more energy is required to escape the basin of attraction. The landscape at the back is a cartoon of how we interpret the current situation: as the basin of attraction of the status quo has shrunken, temporal shifts of social groups or entire nations to alternative configurations become easier and more frequent.

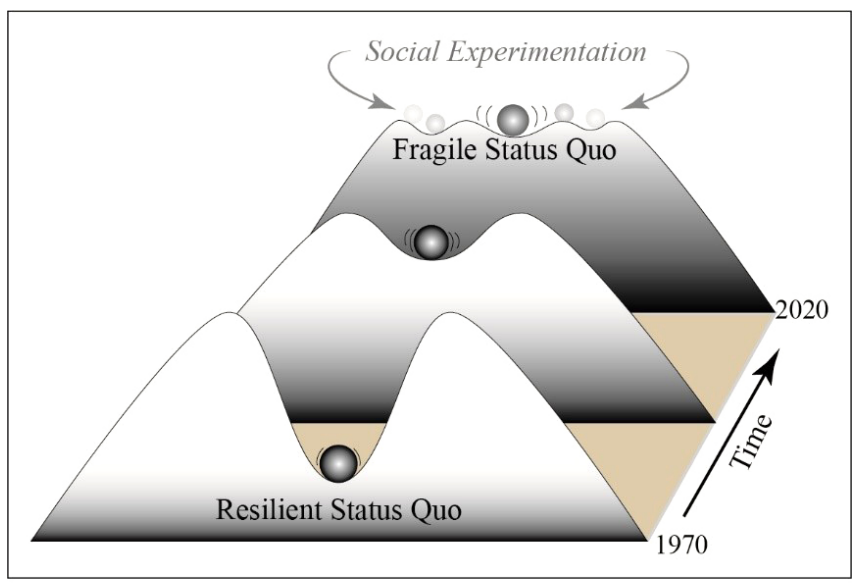

Now imagine what happens as the attractiveness of the status quo deteriorates. One aspect of such deterioration may be a rise of societal tension, although, again, there is obviously a complex of factors involved here. Such a decrease of attractiveness will imply 
a decrease of resilience of the status quo, in the sense that it will take longer for the system to settle back in the deepest point upon perturbations (the slopes toward the deepest point are less steep). Also, alternative configurations may become attractive, inviting small or larger scale social experiments (the alternative valleys in the stability landscape at the back). Such experimentations may thus be seen as flickering in terms of dynamical systems theory. Some of the flickering may be fads, brief, contagious enthusiasms, like in diets, clothing, hairstyles, music, based perhaps more in a desire to belong (identity) than to problem solution. Other flickerings, governed by a different dynamic, may result in real social innovation, deeper and more resilient alternative basins of attraction with greater promise of sustainability, e.g., the Transition Town movement. For a one-dimensional system, i.e., with only one state variable such as openness of economy, or proportion of vegetable food in the diet, one could in principle model a corresponding system with a differential equation, and compute the stability landscapes. In such a model the slopes correspond to the derivative of the model in time, and the hilltops and valleys are states where this derivative is zero. For a further formal treatment of how this works one may refer to one of the textbooks on dynamical systems (Strogatz 1994, Scheffer 2009). Here we just loosely follow the analogy to have a visual support for our central argument. We see the balls jumping to small alternative valleys as experiments with alternative configurations by countries, e.g., electing a populist isolationist leader, or societal subgroups, e.g., becoming vegan or focusing on alternative economic tools.

\section{EXPLORATION: NECESSARY AND UNCOMFORTABLE}

Although simple models can help understand how complex systems destabilize and then develop in new ways, they leave two core questions open: (1) How do we distinguish between social fads/crazes and social innovation? And (2) What are the deep human drivers behind each?

A review of the literature on fads and crazes reveals a number of common characteristics (Aguirre et al. 1988). Fads are (1) homogeneous across time and space; (2) involving novelty; (3) odd when compared to dominant cultural norms, evoking disapproval; (4) nonutilitarian and lacking in significant consequences for participants or the broader society; (5) sudden, involving little deliberate planning and preparation; (6) spreading rapidly; (7) short-lived. Transformative social innovations, on the other hand although also involving novelty and initially seeming odd when compared to dominant cultural norms, involve much deliberate planning, preparation, and creativity, may not spread, but if managed strategically over time and in response to emerging possibility can have enormous consequences for the broader social-ecological system (Westley et al. 2017).

A key way to distinguish fads and crazes from transformative social innovation is to identify the drivers of those engaged in the two forms of social action. Social innovators are deeply committed not only to generating new solutions to social problems, but also to ensuring those solutions ultimately transform the social institutions that created the problem in the first place. Social innovators can be idealists with a longing for a better world, but they are also pragmatists who work strategically to secure the resources required to make change happen. They are rarely driven by fear or by escapism (Westley et al. 2013).
Those who are drawn to fads and crazes on the other hand, "share predispositions in the form of anxieties, ambiguities, and strains that are resolved through the development and resolution of a collective fantasy" (Aguirre et al. 1988:571). And although we need social innovators as we approach this tipping point, it is through understanding the drivers behind the shallow experimentation that we understand how the looming crises of our environment is producing such behavior, counterproductive as it may ultimately be.

Drivers of human behavior are multiple and complex. However, social psychologists in recent years have been building a substantial body of evidence that our fear of our own mortality is fundamental. Over 40 years ago, the anthropologist Ernst Becker, in a seminal work argued that "of all things that move man, one of the principal ones is his terror of death" (Becker 1973:11). This idea has its intellectual roots in the sociology and psychology of religion, a subject explored in depth by early social scientists. In the last 30 years, however, the field of terror management theory (TMT) has attracted theorists and researchers from many fields, and has developed a robust set of hypotheses about how human behavior is motivated and (sometimes) manipulated.

The central argument of TMT is that humans seek to reduce and/ or manage this terror of death through a number of strategies. The first is through strong identification with a worldview held by others, which takes on a sacred status and allows the individual to self-transcend. Another is to build up the individual self-esteem and self-worth as a buffer against the terror. TMT defines selfesteem as "the individual's assessment of the extent to which he or she achieves certain standards of value associated with the cultural worldview to which he or she subscribed." (Pyszczynski et al. 2015:6).

Reminders of mortality (what TMT theorists call "death primes") are likely to first harden the strength with which an individual or group holds to their cultural world view and maximize the behavior associated with meeting the standards of value of that world view. For example, if a group believed that climate scientists threaten those who believe in a beneficent universe, they will harden their view that this science is wrong, or that scientists are lying. They will continue to consume because it strengthens their sense of self-worth. TMT goes further to suggest, again following Becker, that the search for self-esteem would extend to hero narratives and immortality projects. These could take the form of extreme allegiance to sport teams, political movements, rock bands, all of which have a larger-than-life quality, to untrammeled consumerism, which the advertising world suggests can elevate our status and self-esteem (Dickinson 2009), and to fads and crazes through which people momentarily escape the sense of threat. It would also extend to lifestyle movements. These movements, such as gender identification, veganism, and minimalism may attract many adherents, particularly among the young, and last a considerable period of time. Consistent with TMT, their chief function appears to be to involve participants in moral identity work, or efforts to define themselves as "worthwhile and good people" (Grigsby 2004:20). Although this work may result in action, like the immortality and hero projects described above, it is largely focused on living a meaningful life in community. 
In our view, dancing on the volcano, as a state in which worldviews or religions have lost their compelling quality, makes humans vulnerable to re-experiencing their terror of death. Without recourse to traditional religious beliefs, and with traditional identities (political, role based, morality based) under attack, TMT would suggest that strategies that point to the precarious nature of our environment (global warming, ocean pollution, etc.) combined with economic and political instability will be experienced, even more intensely than usual, as "death primes." It could be argued that as we enter the Anthropocene we are entering a period in our collective history unlike any we have experienced before.

We are likely in these situations to engage in a somewhat frantic search of new identities, new moral certainties, new protocols for achieving self-esteem on the one hand, and a retreat to "fundamentalist" certainties on the other. Although we argue that this is a time for healthy and generative social innovation, TMT suggests that anxiety will tend to reduce real exploration and sustainable innovation. Instead, anxious individuals may resort to "consensual hallucinations," fads, "vindictive protectiveness," fundamentalism, or lifestyle movements in a desire to create proxy world views and self-esteem (Lukianoff and Haidt 2018). It is the very success of such movements in reducing anxiety that makes it problematic in terms of the transformative social innovation we require.

Times of exploration are an essential part of building general resilience for living with uncertainty and change (Holling 1986, Walker et al. 2009). General resilience is the capacity of socialecological systems to adapt or transform under a broad spectrum of unfamiliar and unpredictable stresses (Carpenter et al. 2012). General resilience lies in the capacity of a social system to engage in second- and third-order change (Bartunek and Moch 1987). This capacity is based on an intense level of social reflexivity that permits the changing the rules of the game as it were, when that game is no longer working (Moore et al. 2018). When this capacity is weak or absent, then a sharp shock to the specific system (a dominant belief, political or economic system), may result in system collapse, a rush to charismatic leaders that promise alternatives, or reactionary "snap back," a hardening of traditions and defense of institutions that in fact are deeply in need of change.

At times of real or felt crisis, when threats to our life and way of life feel very real, we need general resilience. However, these are exactly the times when we are most likely to shut down our capacities for exploration, resorting to "group think," whether reactionary or escapist (Janis 1989). Such responses can provide an illusory sense of safety and protection but produce a system not capable of sustaining itself. These responses also short change the necessary innovation. Neither an overly rational response nor an overprotective one will benefit our future.

\section{FINDING THE WAY}

Building general resilience of exploratory processes is a major challenge of dancing on the volcano. Conditions that enable general resilience include diversity, modularity, openness, reserves, feedbacks, nestedness, monitoring, leadership, and trust (Biggs et al. 2015). It also includes patience, memory, transparent communication, and reflexivity (Edwards 2010, Walker and Westley 2011). By nurturing general resilience, we can maintain a culture of healthy experimentation.
A key aspect of generative experimentation, as opposed to identity-seeking fads, is to imagine alternative futures (van der Heijden 1996, Garb et al. 2008). But a sense of discontinuity with the past accompanies rapid changes in climate, earth's life support systems, and democratic institutions and we lose a generative relationship to memory. Because memory and imagination of the future are linked, we are threatened with diminished capacity for healthy experimentation (Fernyhough 2013). Although social memory, structured and limited as it is by language and convention, can be an impediment to creative, "out of the box" thinking, it is also true that at an individual, neurological level, the loss of memory capacity through brain damage is linked to the loss of capacity to imagine the future (Schacter and Addis 2007). Disruptive change, in the extreme, can potentially reduce our capacity for creative solutions, and so, of course, can the allegiance to overly rigid convention.

The time may be ripe for new ways of combining familiar realities such as norms, traditions, narratives, and identities with new meanings, with the deepest symbolic structures (Anderies et al. 2013, Hall and Lamont 2013). The perception of a life on the plateau and dancing on the volcano may help guide the significance of shifts in deeper meanings of existence. We may realize that well-being (physical and psychological health, material sustenance, and the sense of dignity and belonging that comes with being a recognized member of the community or society) is fundamentally embedded within and dependent upon a healthy and dynamic biosphere. Such "collective imaginaries," i.e., representations that draw their authority from an empirical foundation, significant experiences of a community, and nonrational roots (Bouchard 2015), play essential roles in guiding human motivation and action. Imagining a collective future always involves beliefs about values, norms, and ways of life that characterize a society (Jasanoff and Kim 2015). Questions and visions of how life ought to be lived form the centerpiece of the need for and direction of change (Milkoreit 2017).

Most of all we need for people of very different worldviews to find ways to talk and work together about desirable common futures in a time of extraordinary change (Ellis 2018). We need to be able to connect across diversity, and we need to engage our collective imaginations (Plastrik et al. 2014). Fortunately, there is evidence that alongside the spurious fads and reactions, social innovation is occurring all over the world, and some of this will be sustainable (Bennett et al. 2016, Hawken 2017, Westley et al. 2017).

The plateau of change and uncertainty is not the end of the world as we know it, it is the beginning of shared work toward a better planet than we now have. Progress toward a better planet begins with open conversation about how we will share the planet with each other and all of life on earth.

\section{SUMMARY}

1. When complex systems are in transition between stable pathways, their dynamics are unstable and variable, capable of exploring many alternative pathways, and could move in unpredictable ways toward a surprising pathway.

2. The Earth system is currently unstable in many dimensions: the human population is unsustainable at current consumption levels, climate is changing beyond the range experienced in human evolutionary history, soil and water 
are also degrading, and key elements of the biosphere that support human life are disappearing. Plausible pathways are many, and include the collapse of global civilization or transformation to a new social organization that is sustainable by the life support provided by the biosphere.

3. In this time of reorganization of the earth system, human social dynamics also display characteristics of unstable complex systems. Behavior is diverse, variable, and unpredictable. Some trends are backward-looking. A current example is the attempt to restore the coal industry in the U.S. by the Trump administration. Another is the movement by the UK to leave the E.U. Other trends are forward-looking. Examples are the "Green New Deal" in the U.S., carbon-neutral movements around the world, and diverse social movements. Scales of exploration range from individual behavior to broad international social movements. In this time of turbulence, many pathways are explored and outcomes are unpredictable.

4. As researchers, we are prone to feel that society should be as influenced by data and rational arguments as we are. However, in some respect it seems as if we are speaking to a deaf audience, who seem to be involved either in fundamentalist retreats or in a kind of "fiddling while Rome burns," a proliferation of lifestyle movements, hero projects, and immortality projects that seem from the outside as selfindulgent. How can we understand this? Only by reaching for the underlying drivers of human behavior. Terror management theory offers one explanation of those drivers: fear of death. At the same time, the seeds of real progress of change seem to start growing, reflected in new strategies, changing the rules of the game, and creating new meanings.

5. In a phase of turbulent experimentation, there are dangers and opportunity. Dangers include looking to the past to solve novel future problems or embracing a shiny new idea before it is tested adequately in safe-fail experiments. Opportunities, including innovations that help humans and the living earth that supports them, build resilience into an uncertain future.

Responses to this article can be read online at: http://www.ecologyandsociety.org/issues/responses. php/10839

\section{Acknowledgments:}

Sequence of authors is alphabetic; all authors contributed equally to the manuscript. We acknowledge the volcanoes of Iceland as a source of inspiration. The Spinoza Prize awarded to Marten Scheffer by the Netherlands Organization for Scientific Research made the collaboration possible. We also thank the Beijer Foundation, the Erling-Persson Family Foundation, and the Marianne and Marcus Wallenberg Foundations (C.F.), and WARF and Hilldale awards (SRC). All authors are Beijer Fellows and also engaged with the Stockholm Resilience Centre..

\section{LITERATURE CITED}

Aguirre, B. E., E. L. Quarantelli, and J. L. Mendoza. 1988. The collective behavior of fads: the characteristics, effects, and career of streaking. American Sociological Review 53(4):569-584. http:// dx.doi.org/10.2307/2095850

Anderies, J. M., C. Folke, B. Walker, and E. Ostrom. 2013. Aligning key concepts for global change policy: robustness, resilience, and sustainability. Ecology and Society 18(2):8. http:// dx.doi.org/10.5751/ES-05178-180208

Bartunek, J. M., and M. K. Moch. 1987. First-order, secondorder, and third-order change and organization development interventions: a cognitive approach. Journal of Applied Behavioral Science 23(4):483-500. http://dx.doi.org/10.1177/002188638702300404

Becker, E. 1973. The denial of death. Free Press, New York, New York, USA.

Bennett, E. M., M. Solan, R. Biggs, T. McPhearson, A. V. Norström, P. Olsson, L. Pereira, G. D. Peterson, C. RaudseppHearne, F. Biermann, et al. 2016. Bright spots: seeds of a good Anthropocene. Frontiers in Ecology and the Environment 14 (8):441-448. http://dx.doi.org/10.1002/fee.1309

Biggs, R., G. D. Peterson, and J. C. Rocha. 2018. The Regime Shifts Database: a framework for analyzing regime shifts in socialecological systems. Ecology and Society 23(3):9. http://dx.doi. org/10.5751/ES-10264-230309

Biggs, R., M. Schlüter, and M. L. Schoon, editors. 2015. Principles for building resilience: sustaining ecosystem services in socialecological systems. Cambridge University Press, Cambridge, UK. http://dx.doi.org/10.1017/CBO9781316014240

Bouchard, G. 2015. Social myths and collective imaginaries. University of Toronto Press, Toronto, Ontario, Canada. http:// dx.doi.org/10.3138/9781442625730

Brock, W. A., and S. R. Carpenter. 2010. Interacting regime shifts in ecosystems: implication for early warnings. Ecological Monographs 80(3):353-367. http://dx.doi.org/10.1890/09-1824.1

Carpenter, S. R., K. J. Arrow, S. Barrett, R. Biggs, W. A. Brock, A.-S. Crépin, G. Engström, C. Folke, T. P. Hughes, N. Kautsky, et al. 2012. General resilience to cope with extreme events. Sustainability 4(12):3248-3259. http://dx.doi.org/10.3390/su4123248

Carpenter, S. R., J. J. Cole, M. L. Pace, R. Batt, W. A. Brock, T. Cline, J. Coloso, J. R. Hodgson, J. F. Kitchell, D. A. Seekell, L. Smith, and B. Weidel. 2011. Early warnings of regime shifts: a whole-ecosystem experiment. Science 332(6033):1079-1082. http://dx.doi.org/10.1126/science.1203672

Dickinson, J. L. 2009. The people paradox: self-esteem striving, immortality ideologies, and human response to climate change. Ecology and Society 14(1):34. https://doi.org/10.5751/ES-02849-140134

Edwards, C. 2010. Resilient nation. Demos, London, UK.

Ellis, E. C. 2015. Ecology in an anthropogenic biosphere. Ecological Monographs 85(3):287-331. http://dx.doi. org/10.1890/14-2274.1

Ellis, E. C. 2018. Science alone won't save the earth; people have to do that. New York Times, 11 August. 
Feola, G. 2015. Societal transformation in response to global environmental change: a review of emerging concepts. Ambio 44 (5):376-390. http://dx.doi.org/10.1007/s13280-014-0582-Z

Fernyhough, C. 2013. Pieces of light: how the new science of memory illuminates the stories we tell about our pasts. HarperCollins, New York, New York, USA.

Folke, C., S. R. Carpenter, B. Walker, M. Scheffer, T. Chapin, and J. Rockström. 2010. Resilience thinking: integrating resilience, adaptability and transformability. Ecology and Society 15(4):20. http://dx.doi.org/10.5751/ES-03610-150420

Garb, Y., S. Pulver, and S. VanDeVeer. 2008. Scenarios in society, society in scenarios: toward a social scientific analysis of storyline-driven environmental modeling. Environmental Research Letters 3(4):045015. http://dx.doi.org/10.1088/1748-9326/3/4/045015

Grigsby, M. 2004. Buying time and getting by: the voluntary simplicity movement. State University of New York Press, Albany, New York, USA.

Hall, P. A., and M. Lamont, editors. 2013. Social resilience in the neoliberal era. Cambridge University Press, Cambridge, UK. http://dx.doi.org/10.1017/CBO9781139542425

Hawken, P. 2017. Blessed union: how the largest movement in the world came into being and why nobody saw it coming. Viking, New York, New York, USA.

Hendry, A. P., K. M. Gotanda, and E. I. Svensson. 2017. Human influences on evolution, and the ecological and societal consequences. Philosophical Transactions of the Royal Society B: Biological Sciences 372:20160028. http://dx.doi.org/10.1098/ $\underline{\text { rstb.2016.0028 }}$

Holling, C. S. 1986. The resilience of terrestrial ecosystems: local surprise and global change. Pages 292-317 in W. C. Clark and R. E. Munn, editors. Sustainable development of the biosphere. Cambridge University Press, Cambridge, UK.

Janis, I. 1989. Crucial decisions: leadership in policymaking and crisis management. Free Press, New York, New York, USA.

Jasanoff, S., and S.-H. Kim. 2015. Dreamscapes of modernity: sociotechnical imaginaries and the fabrication of power. University of Chicago Press, Chicago, Illinois, USA. http://dx.doi. org/10.7208/chicago/9780226276663.001.0001

Lukianoff, G., and J. Haidt. 2018. The coddling of the American mind. Penguin, London, UK.

Milkoreit, M. 2017. Imaginary politics: climate change and making the future. Elementa: Science of the Anthropocene 5(62). http://dx.doi.org/10.1525/elementa.249

Moore, M.-L., P. Olsson, W. Nilsson, L. Rose, and F. Westley. 2018. Navigating emergence and system reflexivity as key transformative capacities: experiences from a Global Fellowship Program. Ecology and Society 23(2):38. http://dx.doi. org/10.5751/ES-10166-230238

Mora, C., R. L. Rollins, K. Taladay, M. B. Kantar, M. K. Chock, M. Shimada, and E. C. Franklin. 2018. Bitcoin emissions alone could push global warming above $2^{\circ} \mathrm{C}$. Nature Climate Change 8:931-933. http://dx.doi.org/10.1038/s41558-018-0321-8
Plastrik, P., M. Taylor, and J. Cleveland. 2014. Connecting to change the world: harnessing the power of networks for social impact. Island Press, Washington, D.C., USA.

Pyszczynski, T., S. Solomon, and J. Greenberg. 2015. Chapter one - Thirty years of terror management theory: from Genesis to Revelation. Advances in Experimental Social Psychology 52:1-70. http://dx.doi.org/10.1016/bs.aesp.2015.03.001

Schacter, D. L., and D. R. Addis. 2007. The cognitive neuroscience of constructive memory: remembering the past and imagining the future. Philosophical Transactions of the Royal Society B: Biological Sciences 362(1481):773-786. http://dx.doi.org/10.1098/ rstb.2007.2087

Scheffer, M. 2009. Critical transitions in nature and society. Princeton University Press, Princeton, New Jersey, USA.

Scheffer, M., S. R. Carpenter, T. M. Lenton, J. Bascompte, W. Brock, V. Dakos, J. van de Koppel, I. A. van de Leemput, S. A. Levin, E. H. van Nes, M. Pascual, and J.Vandermeer. 2012. Anticipating critical transitions. Science 338(6105):344-348. http://dx.doi.org/10.1126/science. 1225244

Schlesinger, W. H., and E. S. Bernhardt. 2013. Biogeochemistry: an analysis of global change. Third edition. Academic, Waltham, Massachusetts, USA.

Smelser, N. 1963. Theory of collective behavior. Free Press, New York, New York, USA. http://dx.doi.org/10.1037/14412-000

Steffen, W., J. Rockström, K. Richardson, T. M. Lenton, C. Folke, D. Liverman, C. P. Summerhayes, A. D. Barnosky, S. E. Cornell, M. Crucifix, J. F. Donges, I. Fetzer, S. J. Lade, M. Scheffer, R. Winkelmann, and H. J. Schellnhuber. 2018. Trajectories of the Earth system in the Anthropocene. Proceedings of the National Academy of Sciences 115(33):8252-8259. http://dx.doi.org/10.1073/ pnas. 1810141115

Strogatz, S. H. 1994. Nonlinear dynamics and chaos: with applications to physics, biology, chemistry, and engineering. Addison-Wesley, Boston, Massachusetts, USA. http://dx.doi. org/10.1201/9780429492563

van der Heijden, K. 1996. Scenarios: the art of strategic conversation. John Wiley and Sons, New York, New York, USA.

Walker, B., and F. Westley. 2011. Perspectives on resilience to disasters across sectors and cultures. Ecology and Society 16(2):4. http://dx.doi.org/10.5751/ES-04070-160204

Walker, B. H., N. Abel, J. M. Anderies, and P. Ryan. 2009. Resilience, adaptability, and transformability in the GoulburnBroken Catchment, Australia. Ecology and Society 14(1):12. http://dx.doi.org/10.5751/ES-02824-140112

Westley, F., P. Olsson, C. Folke, T. Homer-Dixon, H. Vredenburg, D. Loorbach, J. Thompson, M. Nilsson, E. Lambin, J. Sendzimir, B. Banerjee, V. Galaz, and S. van der Leeuw. 2011. Tipping toward sustainability: emerging pathways of transformation. Ambio 40 (7):762-780. http://dx.doi.org/10.1007/s13280-011-0186-9

Westley, F., O. Tjornbo, and K. McGowan, editors. 2017. The evolution of social organization Edward Elgar, London, UK.

Westley, F. R., O. Tjornbo, L. Schultz, P. Olsson, C. Folke, B. Crona, and Ö Bodin. 2013. A theory of transformative agency in 
linked social-ecological systems. Ecology and Society 18(3):27. http://dx.doi.org/10.5751/ES-05072-180327

Wheeler, T., and J. von Braun. 2013. Climate change impacts on global food security. Science 341(6145):508-513. http://dx.doi. org/10.1126/science.1239402

Williams, M., J. Zalasiewicz, P. Haff, C. Schwägerl, A. D. Barnosky, and E. C. Ellis. 2015. The Anthropocene biosphere. Anthropocene Review 2(3):196-219. doi:10.1177/2053019615591020 http://dx.doi.org/10.1177/2053019615591020 